\title{
A complex endodontic retreatment
}

\section{Case}

Case report of a re-treatment of the 46. A patient is referred to us with a request to do a re-treatment in element 46.

\section{Diagnosis}

Symptomatic lesions of endodontic origin to both the mesial and distal radix. An X-ray image, what is striking is the lesion that may result after the perforation of the distal wall in the distal radix in the preparation of space for a pin to a cast metal structure. Further, a separated piece of file in $\mathrm{MB}$, insufficient prepared and under the supplemented wort with channels to each portal or exit (POE) a lesion (Figure $1 \& 2$ ). After anesthesia and rubber dam crown was removed first (Figure $3 \& 4$ ). With the aid of hard steel milling cutters, the build-up has been cut through. It must be ensured that the cut through to end the metal in the cement, where the build-up is stuck with it. This is to prevent unnecessary loss of dentin (Figure 5) after separation of the build-up is first removed, the mesial portion and the distal portion thereafter. That's pretty simple with ultrasonic energy (Figures 6-8). The cement residues are removed using an ultrsone tip without refrigeration. After the removal of cement residues and a first cleaning phase is immediately apparent from the pulp chamber to the channel to which the pin is in prepared is not located symmetrically with respect to the outer circumference of the distal radix. So looking for a $4^{\text {th }}$ channel (Figure $9 \& 10$ ). The picture in the distal root canal shows a little bleeding through the perforation (Figure 11). The disto-lingual channel input. (Figure 12) Thereafter, the disto-buccal channel is cleaned of residual cement and gutta percha and cleaned the two channels and filled. It is important to keep the location of the perforation and not lubricate under the gutta percha and sealer.

\author{
Volume 7 Issue I - 2017
}

\author{
Rik van Mill \\ Department of Endodontics, Netherlands
}

Correspondence: Rik van Mill, Department of Endodontics, Parmentierlaan 76A, II85 CZ Amstelveen, Netherlands, Email rik@hjvanmill.nl

Received: March 27, 2017| Published: April 10, 2017

This is easiest when using the 'Squirt' method. It is gutta percha with an obtura or other device directly injected into the channel and condensed (Figure 13-15). The advantage of this is that not to be the first perforation is sealed with MTA waited for after which 24 may be further. That saves a seat and is therefore much more efficient. Now the first part of the canal apical to the perforation geobtureerd and thereafter applying the MTA also much simpler (Figure $16 \& 17$ ) are the final pictures immediately postoperatively. The referring dentist I got three months later one picture control, the patient lives far away, and then it is clear to see the cure (Figure 18). Successful endodontic treatments do 1000000 take small steps in the right direction. How difficult is the case, the smaller the increments. Therefore, I can do sometimes wonder what the legislature has inspired to 4 channels to reward molars with the next rate channel. The $4^{\text {th }}$ channel this element took as much time as the whole further retreatment. Would the $4^{\text {th }}$ channel will be honored as a $1^{\text {st }}$ channel or I would venture the guess that would have filled many more found.

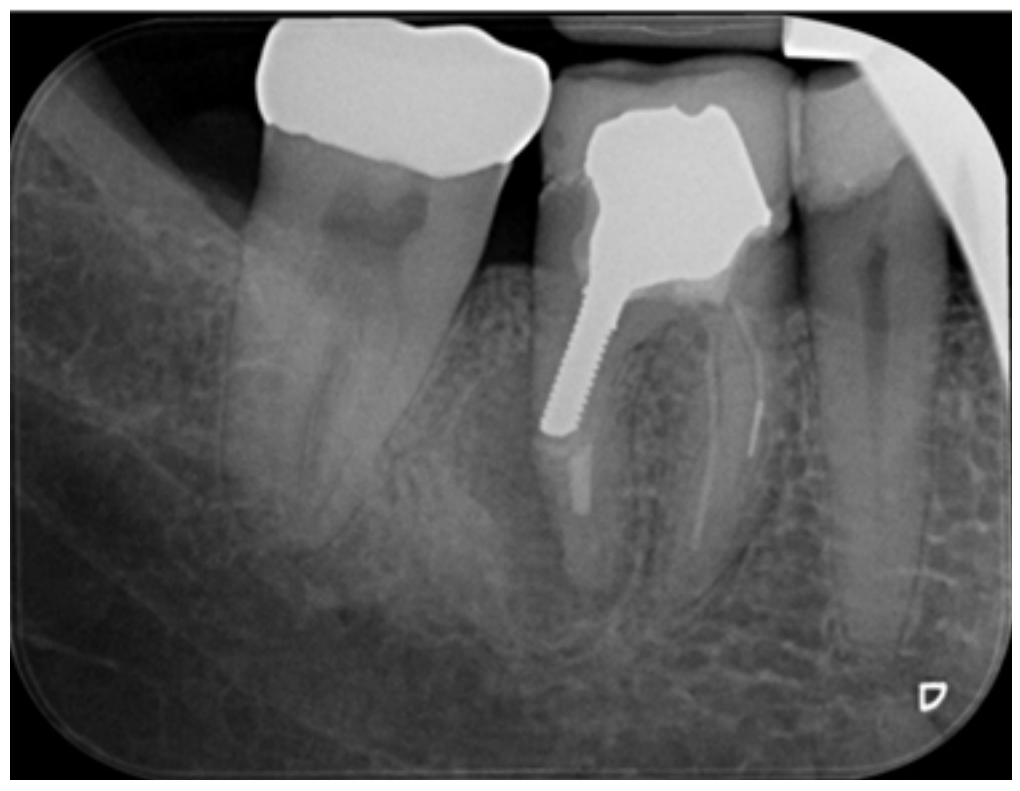

Figure I 


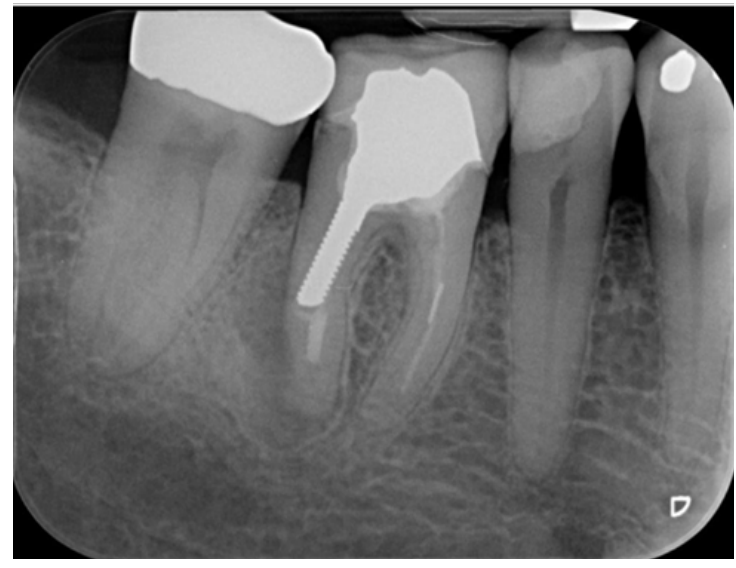

Figure 2

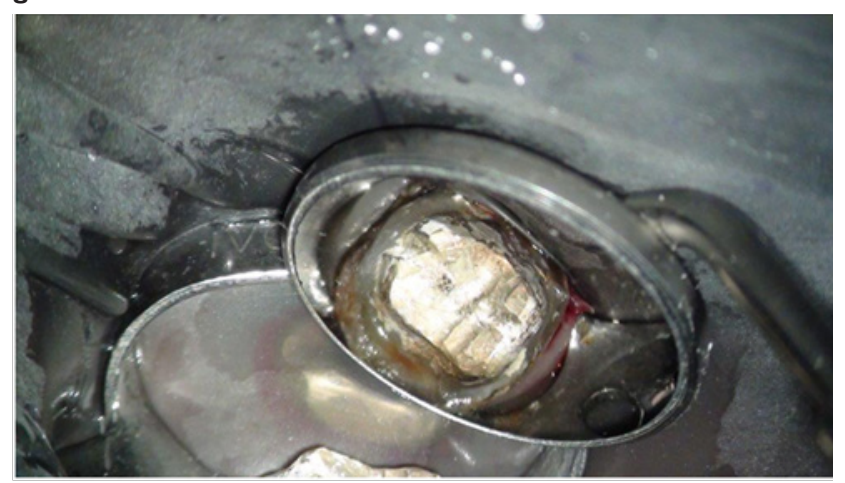

Figure 3

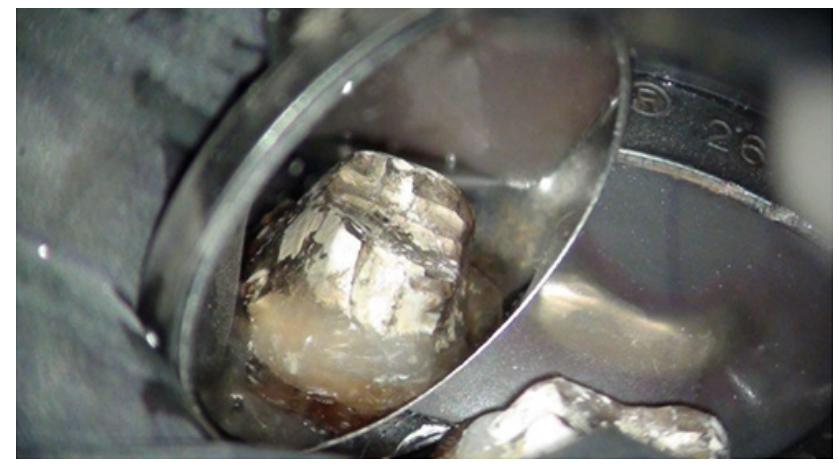

Figure 4

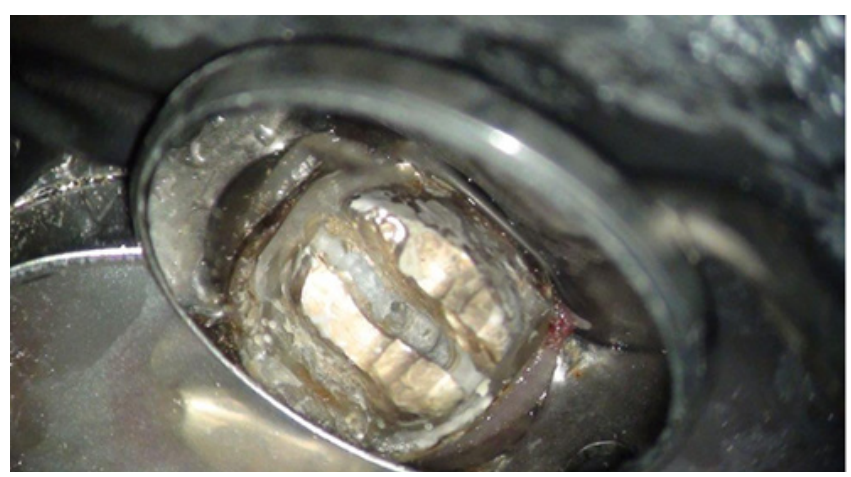

Figure 5

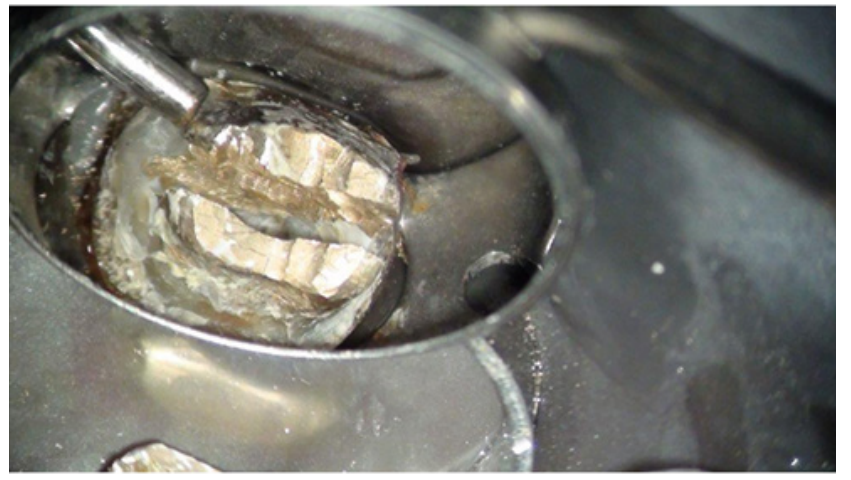

Figure 6

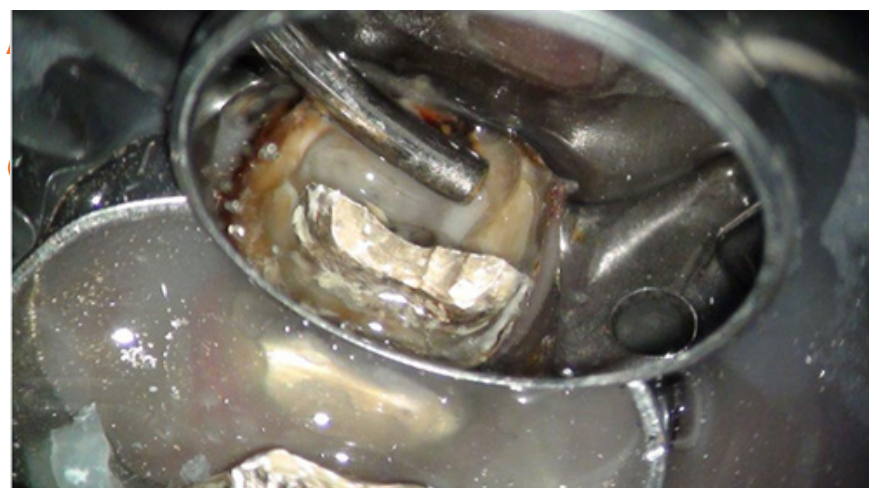

Figure 7

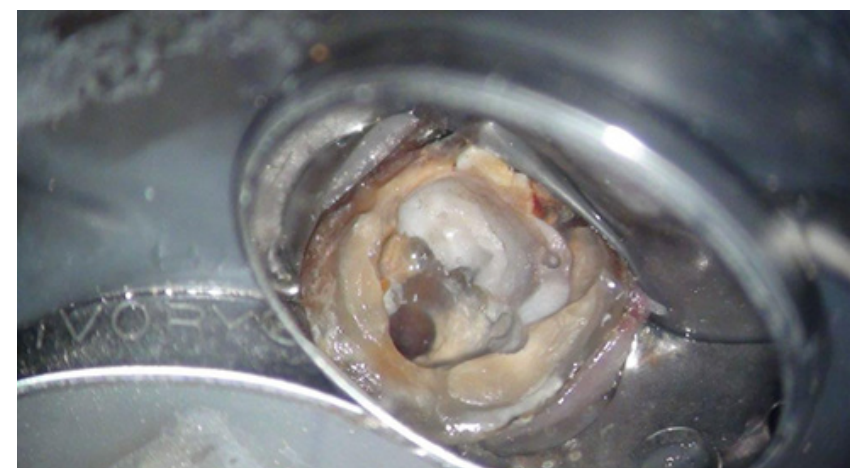

Figure 8

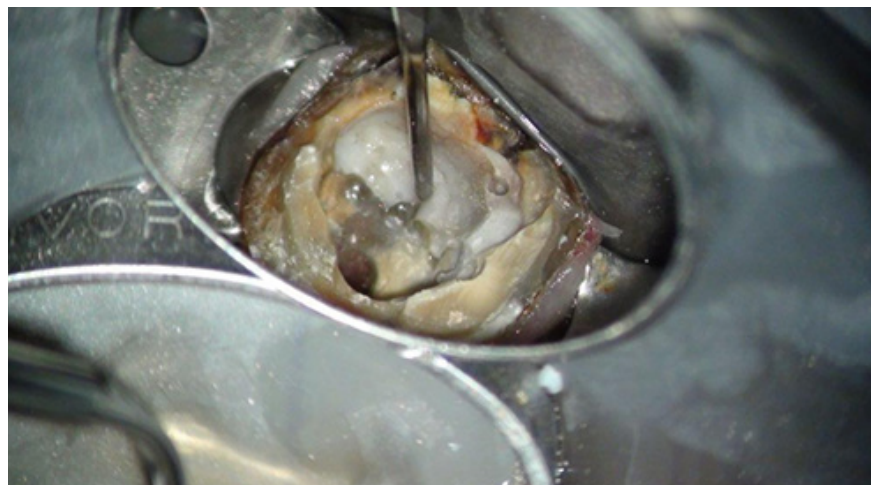

Figure 9 


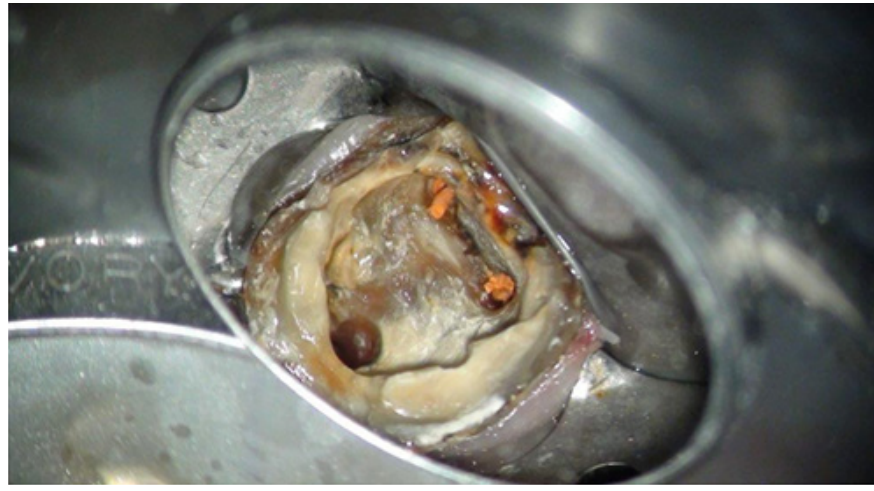

Figure 10

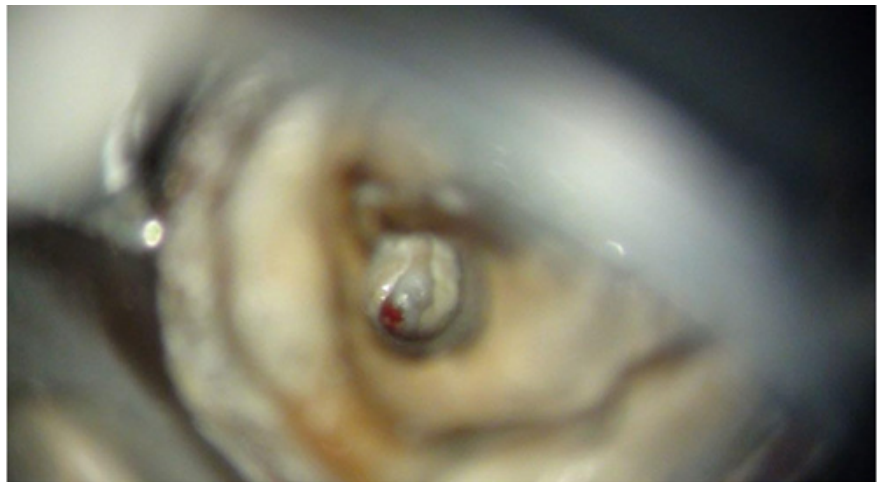

Figure I I

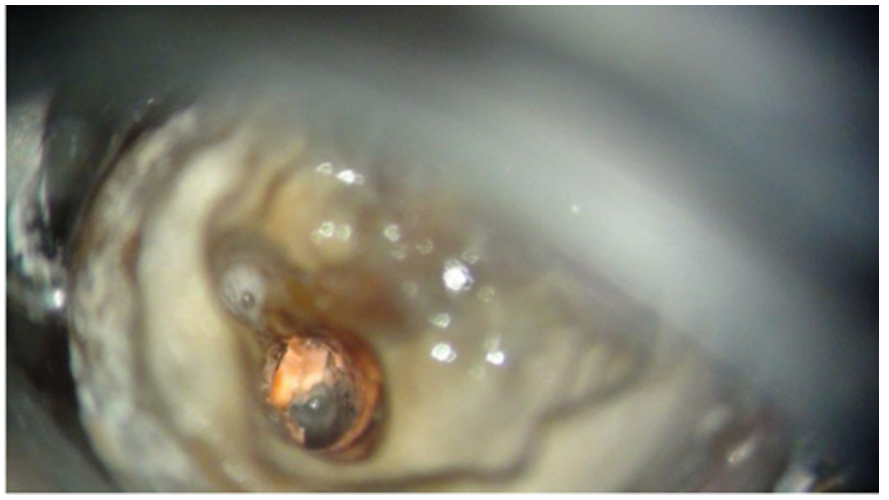

Figure 12

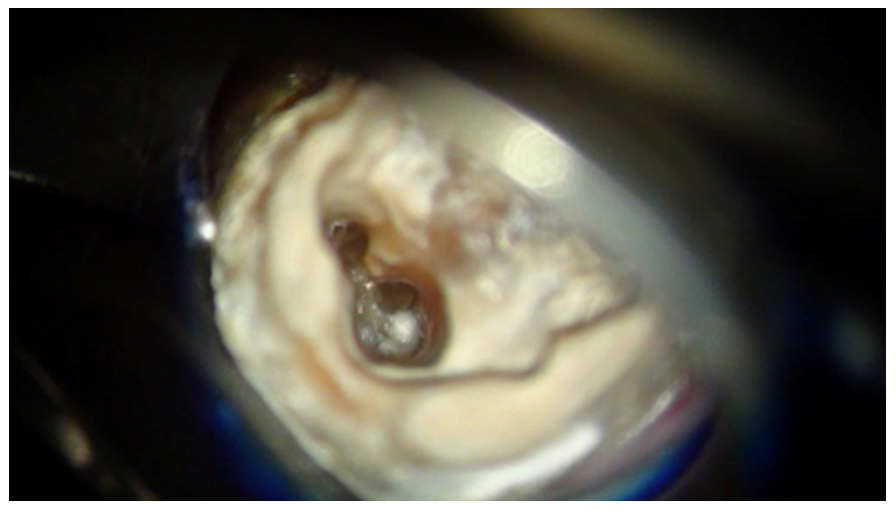

Figure I3

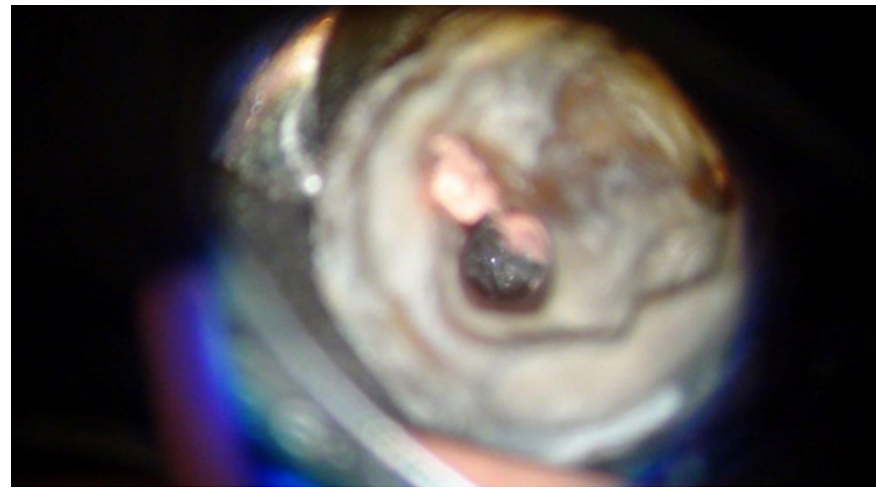

Figure 14

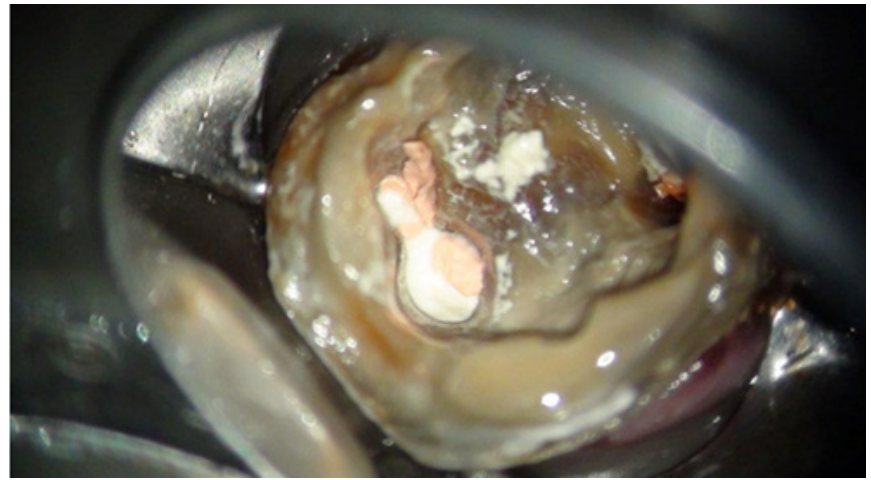

Figure I5

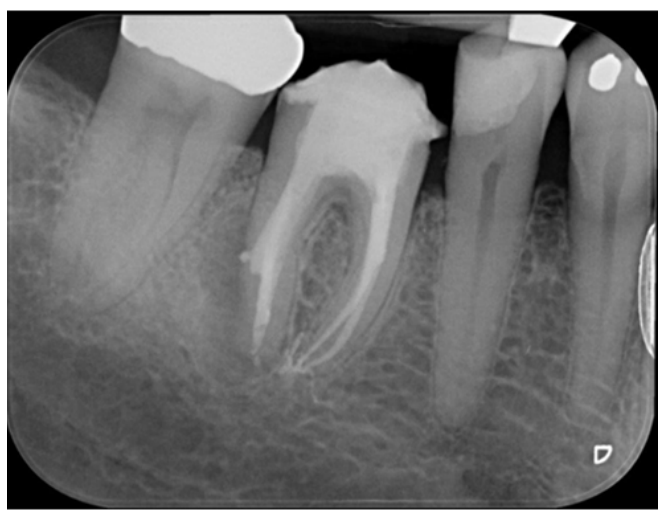

Figure 16

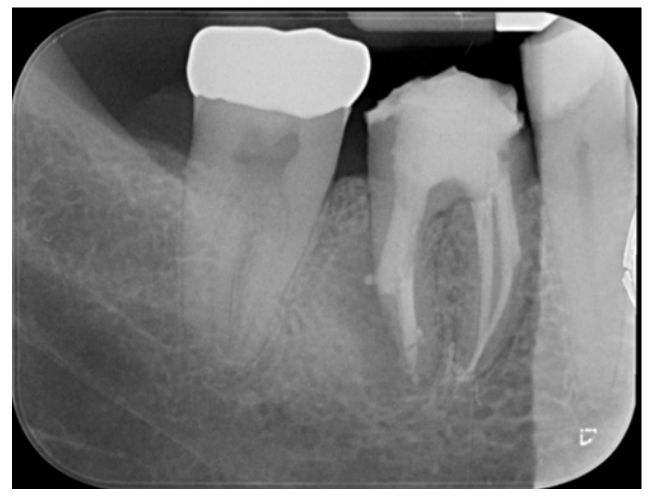

Figure 17 


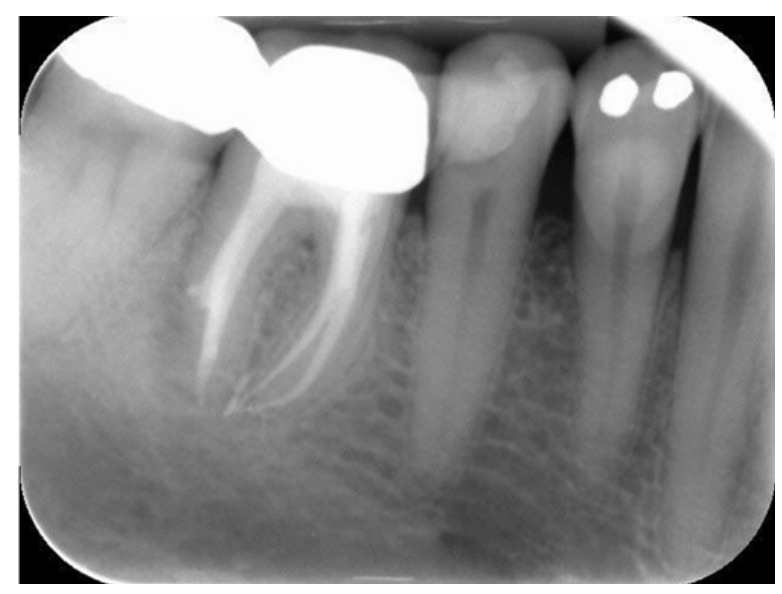

\section{Acknowledgments}

None.

\section{Conflicts of interest}

The authors declare there is no conflict of interest.

Figure 18 